\title{
Ionic conductivity and relaxation studies in PVDF-HFP:PMMA-based gel polymer blend electrolyte with $\mathrm{LiClO}_{4}$ salt
}

\author{
Khushbu Gohel and D. K. Kanchan* \\ Department of Physics, Faculty of Science \\ The M.S. University of Baroda \\ Vadodara 390002, Gujarat, India \\ *dkkanchan.ssi@gmail.com
}

Received 5 January 2018; Revised 8 February 2018; Accepted 12 February 2018; Published 27 February 2018

\begin{abstract}
Poly(vinylidene fluoride-hexafluropropylene) (PVDF-HFP) and poly(methyl methacrylate) (PMMA)-based gel polymer electrolytes (GPEs) comprising propylene carbonate and diethyl carbonate mixed plasticizer with variation of lithium perchlorate $\left(\mathrm{LiClO}_{4}\right)$ salt concentrations have been prepared using a solvent casting technique. Structural characterization has been carried out using XRD wherein diffraction pattern reveals the amorphous nature of sample up to $7.5 \mathrm{wt}$.\% salt and complexation of polymers and salt have been studied by FTIR analysis. Surface morphology of the samples has been studied using scanning electron microscope. Electrochemical impedance spectroscopy in the temperature range 303-363 K has been carried out for electrical conductivity. The maximum room temperature conductivity of $2.83 \times 10^{-4} \mathrm{~S} \mathrm{~cm}^{-1}$ has been observed for the GPE incorporating $7.5 \mathrm{wt} . \% \mathrm{LiClO}_{4}$. The temperature dependence of ionic conductivity obeys the Arrhenius relation. The increase in ionic conductivity with change in temperatures and salt content is observed. Transport number measurement is carried out by Wagner's DC polarization method. Loss tangent $(\tan \delta)$ and imaginary part of modulus $\left(M^{\prime \prime}\right)$ corresponding to dielectric relaxation and conductivity relaxation respectively show faster relaxation process with increasing salt content up to optimum value of $7.5 \mathrm{wt} . \% \mathrm{LiClO}_{4}$. The modulus $\left(M^{\prime \prime}\right)$ shows that the conductivity relaxation is of non-Debye type (broader than Debye peak).
\end{abstract}

Keywords: Gel polymer electrolyte; ionic conductivity; transport number; Wagner's DC polarization; impedance.

\section{Introduction}

The development of ionically conducting polymer electrolytes has increased enormous interest due to a wide range of promising applications in various electrochemical devices such as fuel cells, electrochromic devices, super capacitors, solar cells, especially in acquiring a battery that combines compact shape, long life, low cost, environmental safety, and high energy density. ${ }^{1,2}$ A lithium ion battery consists of anode and cathode as electrodes and polymer electrolyte as separator, through which ion transport phenomenon occurs. The basic requirements for a polymer electrolyte used in a battery are (1) high ionic conductivity, (2) good mechanical strength, (3) wide electrochemical stability window, (4) appreciable $\mathrm{Li}^{+}$transference number, and (5) low electronic conductivity. ${ }^{3}$ In addition to these, the polymer also plays a crucial role in the mechanism of ionic conduction. Polymer matrix with polar groups, such as $-\mathrm{O}-, \mathrm{C}=\mathrm{O},=\mathrm{O},-\mathrm{N}-, \mathrm{C}=\mathrm{N}$, and $\mathrm{C}-\mathrm{F}$ with high dielectric constant have the ability to dissolve salts and formation of polymer-salt complexes which dissociate inorganic salt in the polymer matrix. It increases the effective number of mobile ions that take part in the conduction process. ${ }^{4}$ These polymer electrolytes have a few points of interest, such as no leakage of electrolytes, ease of preparation of polymer into thin films, high energy density, high compatibility, and no electrolytic degradation as compared to carbonate-based liquid electrolytes. However, solid polymer electrolyte using different polymer hosts such as PEO, PVA, PMMA, PVDF possesses very low ionic conductivity which excludes it from practical applications. ${ }^{5}$ As an alternative substitute to replace liquid electrolytes, there has been a great interest in gel polymer electrolytes (GPEs). The GPEs are important electrolyte candidates due to their ionic conductivity of the order of $10^{-4}$ to $10^{-3} \mathrm{~S} \mathrm{~cm}^{-1}{ }^{6}$ GPEs are acquired by incorporation of a certain amount of liquid plasticizer/solvent into the polymer-salt system which has ability to dissolve the salt and maintain liquid state within the polymer matrix so that the transport of ions occurs in the liquid-rich swollen gelled phase. From a practical application point of view, the GPE should possess the properties of good mechanical strength, ability of absorbing the liquid electrolyte, high ionic conductivity, and electrochemical stability toward both electrodes. Various kinds of polymers such as poly(methyl methacrylate) (PMMA), ${ }^{7}$ polyacrylonitrile (PAN), ${ }^{8}$ poly(vinyl chloride) (PVC), ${ }^{9}$ and poly(vinylidene fluoride) (PVDF) ${ }^{10}$ etc. act as host polymers for GPE. All above-said properties of GPE cannot be achieved by using a single polymer as various problems arise, such as poor mechanical strength, compatibility towards lithium

This is an Open Access article published by World Scientific Publishing Company. It is distributed under the terms of the Creative Commons Attribution 4.0 (CC-BY) License. Further distribution of this work is permitted, provided the original work is properly cited. 
metal anode, and poor interfacial properties. ${ }^{11}$ Hence, in the present study, the technique of blending two polymers PVDF-HFP and PMMA is used to improve the properties of the polymer matrix. As a polymer host, PVDF-HFP has received a lot of attention due to its excellent properties such as low degree of crystallinity ${ }^{12}$ and high dielectric constant $\varepsilon \approx$ $8.4^{13}$ that help in higher dissociation of lithium salt. The PVDF-HFP polymer possesses both amorphous and crystalline phases in which the amorphous HFP part can trap large amounts of liquid electrolytes whereas the crystalline $\mathrm{VdF}$ part assists in the improvement of the mechanical stability for the formation of a free-standing film. ${ }^{14}$ PMMA-based GPEs offer high ionic conductivity very close to liquid electrolytes $10^{-3} \mathrm{~S} \mathrm{~cm}^{-1}$ at $25^{\circ} \mathrm{C}$ and even at low temperatures e.g., at $-20^{\circ} \mathrm{C}$, the conductivity remains quite high. ${ }^{7}$ The blending of the polymer increases amorphicity or can hinder the crystalline nature. ${ }^{15,16}$

The plasticizer is a low molecular weight organic solvent which has the ability to dissociate the salt and maintain the liquid state within the polymer matrix. ${ }^{15}$ It also helps increase the amorphous phase in the polymer electrolyte. The dissociation increases the number of free mobile ions which contribute toward the conductivity of polymer electrolyte. Moreover, the addition of plasticizers to GPE also softens the polymer backbone which results in high segmental motion that also assists the movement of ions. Hence, a high dielectric permittivity and low viscosity are essential properties of plasticizers to promote the ion-pair dissociation. Single plasticizer cannot fulfil the requirement of the abovementioned properties. Therefore, in the present study, the mixture of $\mathrm{PC}\left(\varepsilon \approx 64.4\right.$, viscosity at $\left.25^{\circ} \mathrm{C} \approx 2.53 \mathrm{mPa} \mathrm{S}\right)$ and $\operatorname{DEC}\left(\varepsilon \approx 2.82\right.$, viscosity at $25^{\circ} \mathrm{C} \approx 0.748 \mathrm{mPa}$ ) have been taken. Recently, many researchers have reported the various GPEs with various plasticizers to enhance the different properties such as ionic conductivity, structural properties, surface morphology, etc. ${ }^{17,18}$

It is well known that the ionic conductivity of polymer electrolyte depends on the number of charge species and transportation of salt ions occurs through the amorphous region. So, the salt should have low lattice energy and anionic radius so that the ion can diffuse easily through the polymer matrix. Propylene carbonate (PC) and $\mathrm{LiClO}_{4}$ have been used as liquid electrolytes as reported in Ref. 19. The salt $\mathrm{LiCIO}_{4}$ possesses smaller dissociation energy with large anion, thereby providing higher concentration of lithium ions in the electrolyte to conduct. Hence, looking into the development in research field of polymer electrolytes, the present study focusses on the ionic conductivity of the polymer gel electrolyte based on $\mathrm{LiClO}_{4}$ salt by changing the polymer structure by blending and using different amounts of salt dissolved in plasticizers.

Hence, in the present study, we have studied the effect of $\mathrm{LiClO}_{4}$ salt concentration on conduction properties, dielectric properties, and relaxation processes of gel polymer blend electrolyte. The electrolyte films have been characterized by
X-ray diffraction (XRD), Fourier transform infrared spectroscopy (FTIR), Scanning electron microscopy (SEM), and transport number. The AC conductivity provides considerable information on ion dynamics and conductivity relaxation when results are expressed as a function of frequency. The understanding of conduction mechanism and applicability of Jonschers power law and Arrhenius law in the present polymer blend gel electrolyte with $\mathrm{LiClO}_{4}$ salt have been analyzed.

\section{Experimental}

\subsection{Materials and sample preparation}

Poly(vinylidene fluoride-co-hexafluoropropylene) (PVDFco-HFP) with the molecular weight (Mw) of 400,000 from Aldrich and poly(methyl methacrylate) (PMMA) with $\mathrm{Mw}=$ 350,000 from Alfa-Aesar and lithium perchlorate $\left(\mathrm{LiClO}_{4}\right.$, 99.99\%) obtained from Aldrich have been used. The organic solvents PC (anhydrous, 99.7\%) and diethyl carbonate (DEC, anhydrous, 99.7\%) were procured from Sigma Aldrich as plasticizers to prepare GPEs.

The GPE samples of different compositions with variations in salt concentration (listed in Table 1) were prepared by solution casting method. For preparing gel electrolyte films, blend was prepared by dissolving both polymers PVDF-HFP and PMMA (1:1) in acetone. Known amount of $\mathrm{LiClO}_{4}$ salt was dissolved in the plasticizers PC and DEC, which were taken in 1:1 ratio with total amount equal to that of polymers. This electrolyte solution was then mixed into the blend solution for stirring. The solution was stirred until the mixture gets homogeneous in nature. The solution with different amounts of salt was cast onto Teflon Petri dish. The samples were kept above room temperature at about $60^{\circ} \mathrm{C}$ to form the gel in the films and allowed acetone to evaporate slowly. After the evaporation of acetone, free-standing and flexible thin films of thickness of about $0.12-0.14 \mathrm{~mm}$ were peeled off and kept in vacuum desiccators. Then the films were used for different experimental studies.

\subsection{Characterization}

Structural behavior of pure samples and GPE samples is examined by means of XRD analysis. XRD patterns are

Table 1. The various composition of GPE system.

\begin{tabular}{lccc}
\hline $\begin{array}{l}\text { Sample } \\
\text { code }\end{array}$ & $\begin{array}{c}\text { Polymers } \\
\text { PVDF-HFP+ } \\
\text { PMMA (wt.\%) }\end{array}$ & $\begin{array}{c}\text { Plasticizers } \\
\text { PC+DEC (wt.\%) }\end{array}$ & $\begin{array}{c}\mathrm{LiClO}_{4} \\
\text { salt (wt.\%) }\end{array}$ \\
\hline S1 & 49 & 49 & 2 \\
S2 & 48 & 48 & 4 \\
S3 & 47.5 & 47.5 & 5 \\
S4 & 46.25 & 46.25 & 7.5 \\
S5 & 45 & 45 & 10 \\
\hline
\end{tabular}


recorded using BRUKER D2-Phaser with $\mathrm{CuK}$ radiation of wavelength $=1.540$ in $2 \theta$ range of $5-70^{\circ}$ with a step of $0.05^{\circ}$. FTIR study has been carried out on prepared GPE films to investigate the complexation of salt in the blend. FTIR spectroscopic studies are carried out using FTIR 4100 JASCO model in the wave number range of $400-4000 \mathrm{~cm}^{-1}$. The morphological and surface properties of the prepared films are examined by a JEOL JSM-6010LA SEM. The ionic conductivity of the polymer electrolyte films is measured by a high precision Solartron 1260 Impedance analyzer in the frequency range of $1 \mathrm{~Hz}$ to $32 \mathrm{MHz}$ at different temperatures between $303 \mathrm{~K}$ and $363 \mathrm{~K}$. The impedance measurements are carried out by sandwiching the polymer electrolyte films between two stainless steel electrodes under spring pressure. The ionic conductivity of each sample is calculated using the following equation:

$$
\sigma=\frac{t}{R_{b} A}
$$

where $t$ is the thickness of the films, $R_{b}$ is the bulk resistance and $A$ is the area of the electrolyte-electrode contact. The transport number of the samples was measured by using Wagner's DC polarization method. The transport numbers were calculated by using the following equation:

$$
t_{\text {ion }}=1-\frac{i_{e}}{i_{t}},
$$

where $t_{\text {ion }}$ is the ionic transport number, $i_{e}$ and $i_{t}$ are the electronic and total currents, respectively.

\section{Results and Discussion}

\subsection{XRD analysis}

XRD is a powerful tool to determine the crystallinity and structural changes in a polymer electrolyte system. The XRD patterns of (PVDF-HFP:PMMA)-(PC:DEC)-LiClO 4 -based GPE at different $\mathrm{LiClO}_{4}$ concentrations are shown in Fig. 1. Diffraction pattern of $\mathrm{LiClO}_{4}$ shows high intense characteristic peaks which revealed the crystalline nature of the salt. Two peaks at $29.7^{\circ}$ and $38.3^{\circ}$ for the pure PVDF-HFP film have been observed, which confirmed the partial crystallization of PVDF units in the copolymer and overall its semicrystalline nature. ${ }^{20}$

The pattern for pure PMMA shows a broad and less intensive peak at $2 \theta \sim 13.8^{\circ}$ which indicates complete amorphous nature of the PMMA film. From the XRD pattern of GPE samples, it is revealed that the absence of crystalline peaks pertaining to $\mathrm{LiClO}_{4}$ in the polymer complexes confirms the complex formation which seems to occur only in the amorphous phase ${ }^{21}$ that confirms the complete dissolution of the salts in the complex matrix, implying that the salt does not have any separate phases in the electrolyte. Figure 1 shows that the prominent peak of PMMA at $13.8^{\circ}$ disappeared and the intense peaks $2 \theta \approx 29.7^{\circ}, 38.3^{\circ}$ of PVDF-HFP decrease

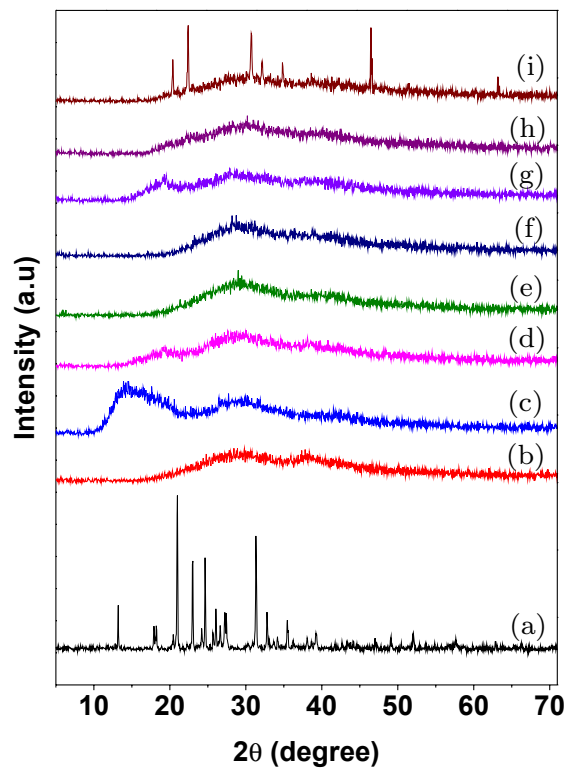

Fig. 1. XRD pattern of (a) $\mathrm{LiClO}_{4}$, (b) pure PVDF-HFP, (c) pure PMMA and (PVDF-HFP:PMMA)-(PC:DEC)- $\mathrm{LiClO}_{4}$ system with $\mathrm{LiClO}_{4}$ content of (d) $0 \mathrm{wt} \%$, (e) 2 wt.\%, (f) 4 wt.\%, (g) 5 wt. $\%$, (h) $7.5 \mathrm{wt} . \%$, and (i) $10 \mathrm{wt} \%$.

together with the broadening and the incorporation of $\mathrm{LiClO}_{4}$ up to $7.5 \mathrm{wt} . \%$ which indicates the increase in the amorphicity of the films. The amorphous phase is maintained up to $7.5 \mathrm{wt} \% \mathrm{LiClO}_{4}$ and on further addition, the crystallinity of the complex is found to be increased.

\subsection{FTIR analysis}

FTIR analysis has been used to identify the nature of bonding, functional groups present in a sample and analyze the interactions among atoms or ions in the electrolyte system. These interactions can induce changes in the vibrational modes of the molecules in the polymer electrolyte. This study has been carried out to analyze the molecular interaction and complexation in the polymer complexes. Figure 2 shows the FTIR spectrum of pure PVDF-HFP, pure PMMA and $\mathrm{LiClO}_{4}$. The FTIR spectra of GPE doped with different concentrations of $\mathrm{LiClO}_{4}$ in the wave number range $400-4000 \mathrm{~cm}^{-1}$ are presented in Fig. 3.

The characteristic fundamental vibrational modes with wavenumbers exhibited by PVDF-HFP, PMMA, and $\mathrm{LiClO}_{4}$ collected from the FTIR experimental spectra are listed in Table 2. PVDF-HFP contains free electron pairs at the fluorine $(\mathrm{F})$ atoms of $\mathrm{CF}_{2}$ and $\mathrm{CF}_{3}$ groups. ${ }^{22}$ The peaks at $509 \mathrm{~cm}^{-1}$ and $435 \mathrm{~cm}^{-1}$ are assigned to the bending and wagging vibrations of $-\mathrm{CF}_{2}$, respectively, and get shifted to $511 \mathrm{~cm}^{-1}$ and $441 \mathrm{~cm}^{-1}$, respectively, with the addition of lithium salt. The characteristic peak of PVDF-HFP at $836 \mathrm{~cm}^{-1}$ corresponds to the vibration of amorphous phase (vinylidene group) shifted to higher frequency at $838 \mathrm{~cm}^{-1}$. 


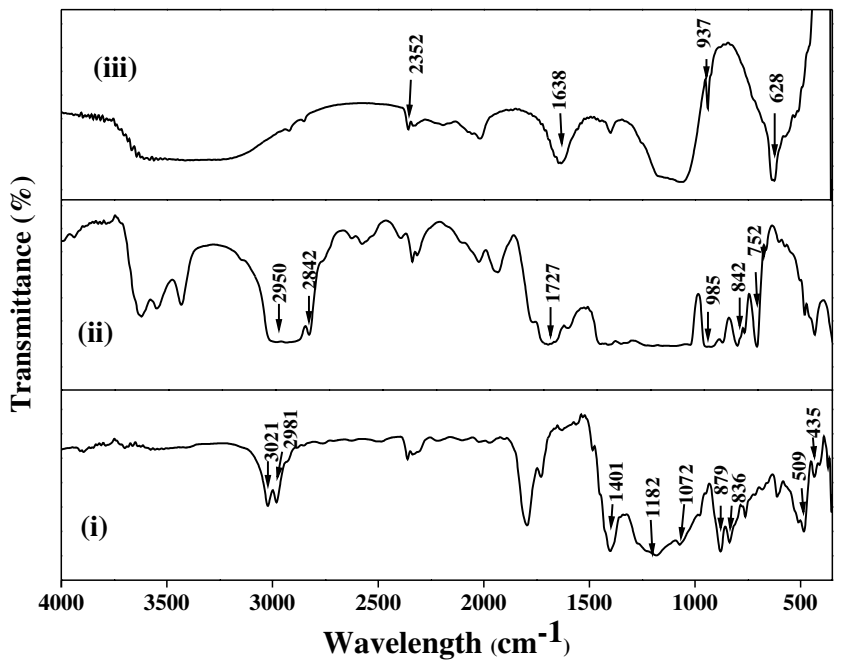

Fig. 2. FTIR spectra of (i) pure PVDF-HFP, (ii) pure PMMA, and (iii) $\mathrm{LiClO}_{4}$.

The characteristics bands of PVDF-HFP at $1401 \mathrm{~cm}^{-1}$ attributed to the crystalline phase are broadened, reduced in intensity and shifted to $1405 \mathrm{~cm}^{-1}$, indicating that interaction occurred between polymers and salt and other crystalline

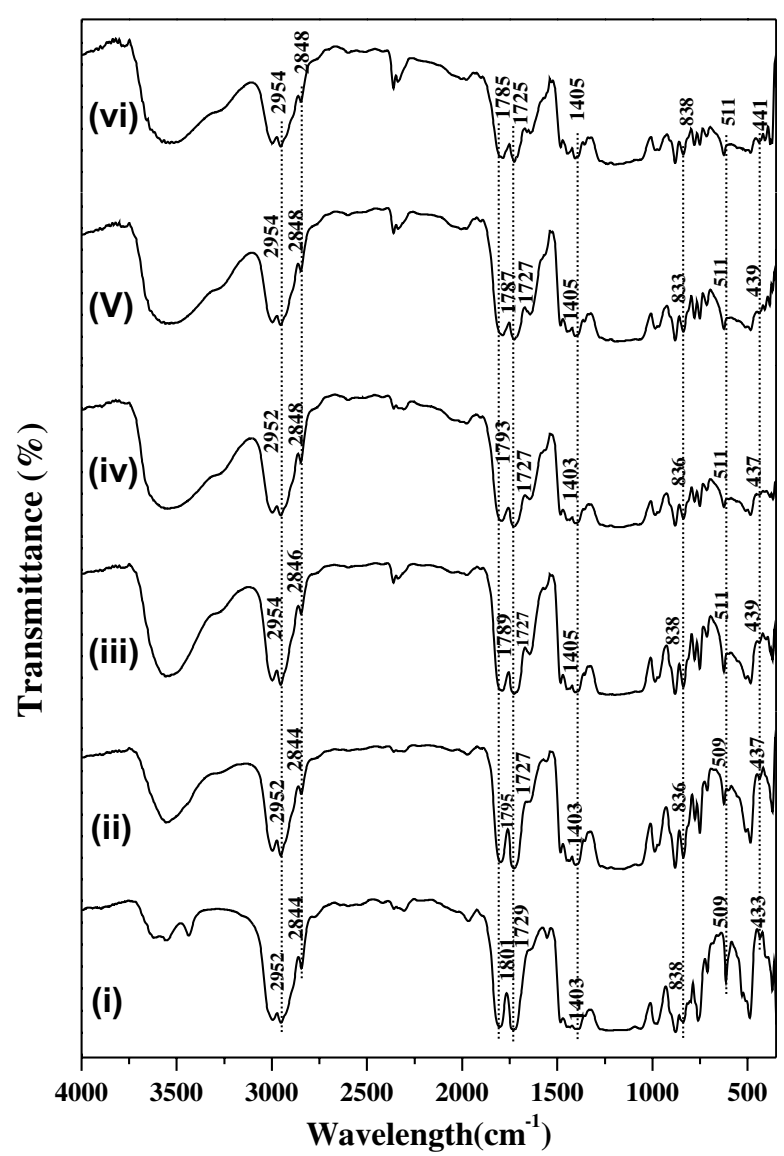

Fig. 3. FTIR spectra of (PVDF-HFP:PMMA)-(PC:DEC)- $\mathrm{LiClO}_{4}$ system with $\mathrm{LiClO}_{4}$ content of (i) $0 \mathrm{wt} . \%$, (ii) $2 \mathrm{wt} \%$, (iii) 4 wt. $\%$, (iv) $5 \mathrm{wt} . \%$, (v) $7.5 \mathrm{wt} . \%$, and (vi) $10 \mathrm{wt} . \%$.
Table 2. Assignment of important bands of PVDF-HFP, PMMA, and $\mathrm{LiClO}_{4}$.

\begin{tabular}{|c|c|c|}
\hline Materials & Wavenumbers $\left(\mathrm{cm}^{-1}\right)$ & Assignment of bands \\
\hline \multirow[t]{6}{*}{ PVDF-HFP } & 3021 & $\begin{array}{l}\text { Non symmetrical stretching of } \mathrm{CH}_{2} \\
\text { group }^{17}\end{array}$ \\
\hline & 2981 & $\begin{array}{l}\text { Symmetrical stretching of } \mathrm{CH}_{2} \\
\text { group }^{17}\end{array}$ \\
\hline & $1401,11182,1072$ & $\alpha$ crystalline phase ${ }^{17}$ \\
\hline & 879,836 & Vibration of amorphous phase ${ }^{17}$ \\
\hline & 509 & $\mathrm{CF}_{2}$ bending ${ }^{17}$ \\
\hline & 484,435 & $\mathrm{CF}_{2}$ wagging $^{17}$ \\
\hline \multirow[t]{5}{*}{ PMMA } & 752 & $\begin{array}{l}\mathrm{CH}_{2} \text { rocking with skeleton } \\
\text { stretching }\end{array}$ \\
\hline & 842 & $\mathrm{C}-\mathrm{H}$ rocking vibration ${ }^{24}$ \\
\hline & 985 & Symmetric stretching C-O bond ${ }^{24}$ \\
\hline & 1727 & $\begin{array}{l}\text { Symmetric stretching of carbonyl } \\
\text { group } \mathrm{C}=\mathrm{O}^{24}\end{array}$ \\
\hline & 2842,2950 & $\mathrm{CH}_{3}$ asymmetric stretching ${ }^{24}$ \\
\hline \multirow[t]{3}{*}{$\mathrm{LiClO}_{4}$} & 628 & stretching vibration of $\mathrm{ClO}_{4}^{-25}$ \\
\hline & 937 & $\begin{array}{l}\text { Symmetrical vibration of ionic pairs } \\
\text { between } \mathrm{Li}+\text { and } \mathrm{ClO}_{4}^{-25}\end{array}$ \\
\hline & 1638,2352 & $\begin{array}{l}\text { Stretching and bending vibration of } \\
\mathrm{OH} \text { bonds for absorbing water }\end{array}$ \\
\hline
\end{tabular}

peaks at $1182 \mathrm{~cm}^{-1}$ and $1072 \mathrm{~cm}^{-1}$ of pure PVDF-HFP reduced in intensity and eventually disappearing when blended with PMMA leading to the suppression of semicrystallinity of PVDF-HFP. It has also been observed that the characteristic peak of pure PVDF-HFP at $1795 \mathrm{~cm}^{-1}$ is shifted to $1785 \mathrm{~cm}^{-1}$. The peak at $2842 \mathrm{~cm}^{-1}$ position associated with $\mathrm{CH}_{3}$ asymmetric stretching vibration of PMMA gets shifted from $2844 \mathrm{~cm}^{-1}$ to $2848 \mathrm{~cm}^{-1}$ and band appearing at $1727 \mathrm{~cm}^{-1}$ is allocated to the symmetrical stretching of the carbonyl group $\mathrm{C}=\mathrm{O}$ in the PMMA backbone that shifts the band toward lower side of the frequency at $1725 \mathrm{~cm}^{-1}$ and intensity is reduced significantly with increasing salt concentrations. This indicates the strong interaction of $\mathrm{Li}$ ions with the carbonyl group of PMMA. Similar observations were also reported by Shukla et al. $^{23}$ in their FTIR studies of lithium salt polymer complexes. Apart from this, the peak at $2950 \mathrm{~cm}^{-1}$ ascribed to $\mathrm{CH}_{3}$ asymmetric stretching is shifted to $2954 \mathrm{~cm}^{-1}$ in the complexes.

In addition, many of the peaks of the polymer electrolyte system disappeared in the IR spectra. The characteristic peaks of pure $\mathrm{LiClO}_{4}$ are found absent in the polymer electrolyte complexes which confirm good complexation of the salt with host polymers. The disappearance or shifting of frequency from pure polymers shows an interaction of the polymers with salt in GPE samples.

\subsection{SEM analysis}

Surface morphology of the GPE films with $\mathrm{LiClO}_{4}$ salt content of $2 \mathrm{wt} . \%, 4 \mathrm{wt} . \%, 7.5 \mathrm{wt} . \%$, and $10 \mathrm{wt} . \%$ are shown in Fig. 4. The image shows uniformly distributed spherical 


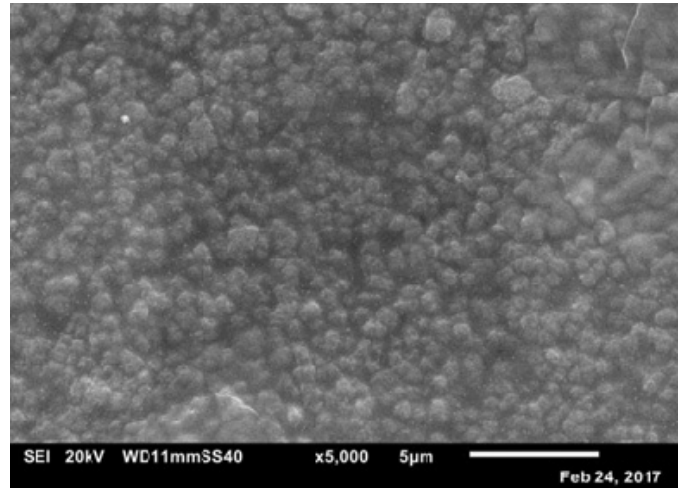

(a)

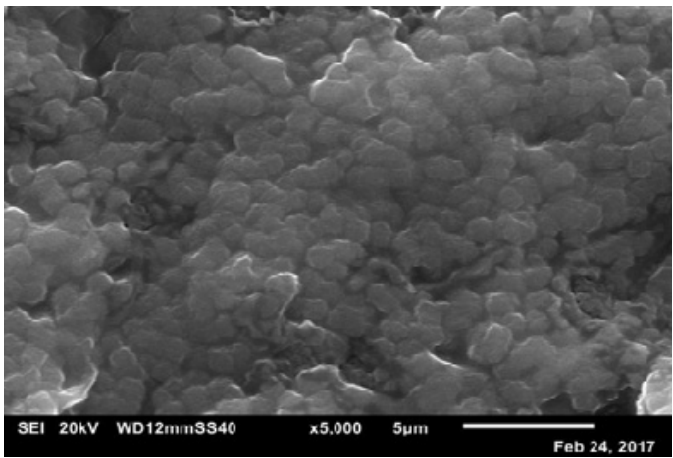

(c)

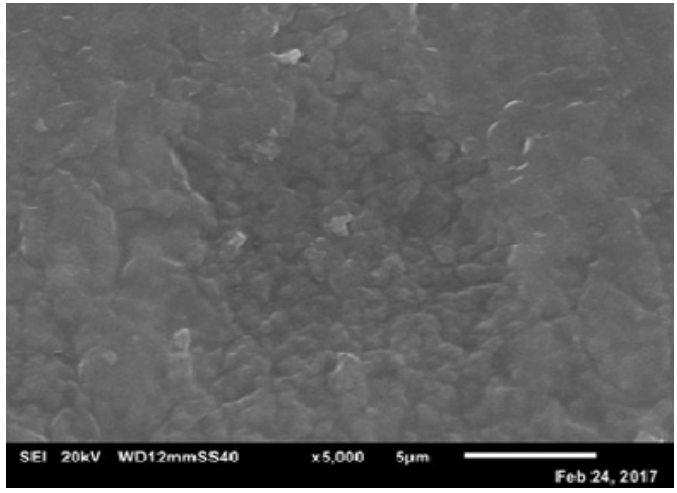

(b)

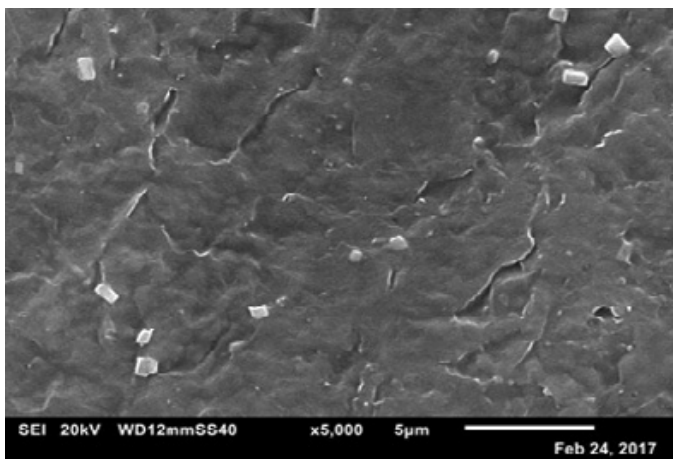

(d)

Fig. 4. SEM micrograph of the GPE films containing (a) 2 wt. $\% \mathrm{LiClO}_{4}$, (b) 4 wt. $\% \mathrm{LiClO}_{4}$, (c) 7.5 wt. $\% \mathrm{LiClO}_{4}$, (d) 10 wt. $\% \mathrm{LiClO}_{4}$.

structures in the GPE film with 2 wt. $\% \mathrm{LiClO}_{4}$. It shows normal porous surface with small pore size. The morphology change to greater pore size when $7.5 \mathrm{wt} \%$ of $\mathrm{LiClO}_{4}$ is doped into the polymer electrolyte. The pores in the polymer complexes help in trapping the large amount of electrolyte solution. Due to this, the swelled nature of the GPE has been observed containing 7.5 wt.\% of $\mathrm{LiClO}_{4}$. The observed feature is very similar to those reported by Ramesh et al. ${ }^{26}$ These microstructures lead to better conducting pathway for $\mathrm{Li}^{+}$ions and consequently higher ionic conductivity.

\subsection{Conductivity analysis}

The electrical properties of the GPE films have been studied using the AC technique of complex impedance spectroscopy (CIS) analysis. Typical complex impedance plot of GPE containing $4 \mathrm{wt} \%$ of $\mathrm{LiClO}_{4}$ at $303 \mathrm{~K}$ along with their equivalent electrical circuit model fitted with experimental values by using EIS spectrum analyzer software is shown in Fig. 5. The complex plot shows a high frequency depressed semicircle portion which corresponds to the parallel combination of resistor $R_{\mathrm{b}}$ (bulk resistor) and a constant phase element CPE1 and a low frequency spike due to the accumulation of charges (double-layer formation) at the electrolyte-electrode (blocking electrode) interface represented by constant phase element CPE2. ${ }^{27}$ Similarly, complex impedance plot for other GPEs at $303 \mathrm{~K}$ for different concentrations of $\mathrm{LiClO}_{4}$ (Fig. 5(inset)) is fitted with equivalent circuit and fitted parameters are listed in Table 3.

It is obvious from Fig. 5(inset) that the intercept of the plots on the real axis $\left(Z^{\prime}\right)$ decreases as the concentration of lithium salt is varied from $2 \mathrm{wt} . \%$ to $7.5 \mathrm{wt} . \%$ and reverse

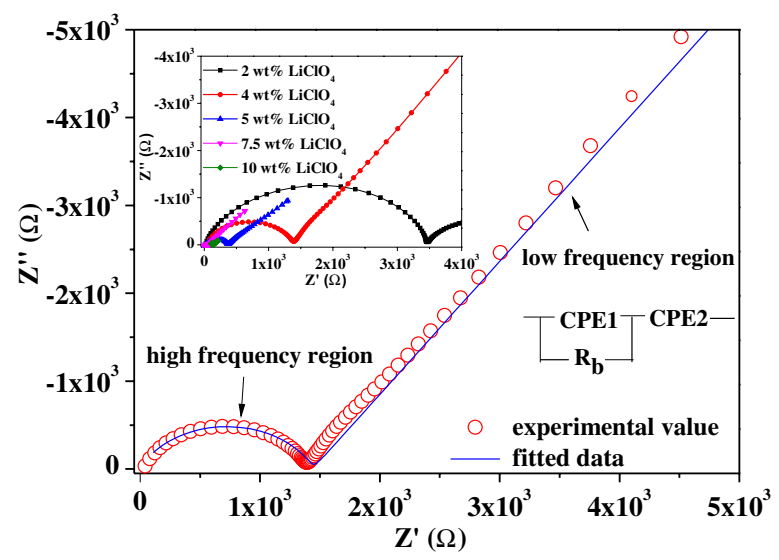

Fig. 5. Impedance plot of GPE containing $4 \mathrm{wt} . \%$ of $\mathrm{LiClO}_{4}$ at $303 \mathrm{~K}$ along with equivalent circuit model (inset impedance plot of GPE with different concentrations of $\mathrm{LiClO}_{4}$ at $303 \mathrm{~K}$ ). 
Table 3. The parameter of circuit element for GPE system with different concentrations of $\mathrm{LiClO}_{4}$ at $303 \mathrm{~K}$.

\begin{tabular}{lccc}
\hline Sample code & Bulk resistance $\left(R_{\mathrm{b}}\right)(\Omega)$ & CPE1 $(\mathrm{F})$ & CPE2 $(\mathrm{F})$ \\
\hline S1 & 3451.1 & $2.346 \mathrm{E}-09$ & $2.218 \mathrm{E}-04$ \\
S2 & 1441 & $4.381 \mathrm{E}-09$ & $3.413 \mathrm{E}-05$ \\
S3 & 324.09 & $2.051 \mathrm{E}-09$ & $2.900 \mathrm{E}-04$ \\
S4 & 72.4 & $2.052 \mathrm{E}-09$ & $3.691 \mathrm{E}-04$ \\
S5 & 138 & $2.977 \mathrm{E}-08$ & $5.000 \mathrm{E}-04$ \\
\hline
\end{tabular}

trend is seen for the $10 \mathrm{wt} . \%$ of $\mathrm{LiClO}_{4}$ salt. From the obtained value of bulk resistance $R_{\mathrm{b}}$, the ionic conductivity of GPE is calculated using Eq. (1) and given in Table 4. From Table 4, it is clear that the conductivity of (PVDF-HFP: PMMA)-(PC:DEC)- $\mathrm{LiClO}_{4}$ system increases upon the addition of lithium salt up to $7.5 \mathrm{wt} \%$. The change in the value of the DC conductivity $\left(\sigma_{\mathrm{DC}}\right)$ can be explained by the theoretical aspects which is given by

$$
\sigma_{\mathrm{DC}}=\sum n_{i} \mu_{i} q_{i}
$$

where $n_{i}$ denotes the charge carrier density, $\mu_{i}$ is the ion mobility and $q_{i}$ is the charge of the $i$ ion. From this equation, the increase in the DC conductivity has been attributed to the increase in the number of mobile charge carriers $n_{i}$ and increase in ion mobility $\mu_{i}$ due to increased amorphous nature of the polymer electrolyte which reduces the potential barrier, thereby facilitating ion transport faster. ${ }^{28}$ XRD result of the present system which shows the increase in amorphous nature is also in good agreement with variation of conductivity. Ramesh et al..$^{29}$ have also reported the increase of amorphicity in PVDF-HFP-based polymer electrolyte with the increasing amount of LiTf salt. As the concentration of salt is increased above $7.5 \mathrm{wt} . \%$, the conductivity is found to decrease due to the formation of ion aggregates. The formation of ion cluster is responsible for the decreased number of charge carrier and hence conductivity.

In the present system, the highest value of DC conductivity of the order of $2.83 \times 10^{-4} \mathrm{~S} \mathrm{~cm}^{-1}$ at $303 \mathrm{~K}$ is obtained for the electrolyte film containing $7.5 \mathrm{wt} . \% \mathrm{LiClO}_{4}$.

\subsection{Temperature-dependent conductivity}

The temperature dependence of ionic conductivity may provide valuable information for ionic conduction behavior. According to Ratner et al., ${ }^{30}$ for polymer electrolyte, the temperature-dependent ionic conductivity generally follows two ion transport models: Arrhenius behavior and Vogel Tammann Fulcher (VTF) behavior. In Arrhenius behavior, the plot of $\sigma$ versus 1000/T is typically linear which is indicative of conduction mechanism via hopping mechanism decoupled from segmental motion of polymer chain. In VTF behavior, it shows nonlinear behavior which indicates that the conduction mechanism involves ion hopping coupled with the polymer segmental motion.

Figure 6 shows that the variation of DC conductivity $\left(\log \sigma_{\mathrm{DC}}\right)$ versus reciprocal temperature $(1000 / T)$ of GPE system with different concentrations of $\mathrm{LiClO}_{4}$ salt.

From the plot, it has been observed that ionic conductivity increases as the temperature increases from $303 \mathrm{~K}$ to $363 \mathrm{~K}$ for all GPE samples. When the temperature increases, the polymer chains get an easy pathway for the motion of segments, which offer channels for the migration of ions resulting in increased ionic conductivity. According to Mathew et al., ${ }^{31}$ in $\mathrm{PVAc} / \mathrm{PVDF} / \mathrm{LiClO}_{4} / \mathrm{X}$, where $\mathrm{X}=\mathrm{DMC}$, DEC, PC, GBL system, with the rise in temperature, the polymer expands and produces free volume so that mobile carriers or polymer chain segments can move through the free volume. In order to give a better understanding of the ionic conduction mechanism of the GPE films, the linear behavior of $\left(\log \sigma_{\mathrm{DC}}\right)$ versus reciprocal temperature $(1000 / T)$ data have been fitted to the Arrhenius relation expressed as

$$
\sigma=\sigma_{0} \exp \left(\frac{E_{a}}{K_{B} T}\right)
$$

where $\sigma_{0}$ is the pre-exponential factor, $E_{a}$ is the activation energy, $K_{B}$ is the Boltzmann constant and $T$ is the temperature in Kelvin. The activation energy is calculated from the slope of the plot and listed in Table 4. The activation energy for sample containing $10 \mathrm{wt} . \% \mathrm{LiClO}_{4}$ is calculated from the slope of fitting line in the temperature region from $303 \mathrm{~K}$ to $328 \mathrm{~K}$.

As can be seen from Fig. 7, the sample with maximum ionic conductivity exhibits minimum activation energy. For

Table 4. Conductivity $\left(\sigma_{\mathrm{DC}}\right)$, activation energy $\left(\mathrm{E}_{\mathrm{a}}\right)$, hopping frequency $\left(\omega_{p}\right)$ and carrier concentration term $(\mathrm{K})$, Relaxation time $\left(\tau_{\tan \delta}\right)$, stretching parameter $(\beta)$ and transport number $\left(\mathrm{t}_{\text {ion }}\right)$ of different GPEs system.

\begin{tabular}{lccccccc}
\hline $\begin{array}{l}\text { Sample } \\
\text { code }\end{array}$ & $\begin{array}{c}\text { Conductivity }\left(\sigma_{\mathrm{DC}}\right) \\
\left(\mathrm{S} \mathrm{cm}^{-1}\right) \text { at } 303 \mathrm{~K}\end{array}$ & $\begin{array}{c}\text { Activation } \\
\text { energy }\left(\mathrm{E}_{\mathrm{a}}\right)(\mathrm{eV})\end{array}$ & $\begin{array}{c}\text { Hopping frequency } \\
\omega_{p}(\mathrm{~Hz})\end{array}$ & $\begin{array}{c}\mathrm{K} \\
\left(\Omega^{-1} \mathrm{~cm}^{-1} \mathrm{~Hz}^{-1} \mathrm{~K}\right)\end{array}$ & $\begin{array}{c}\text { Relaxation time } \\
\tau_{\tan \delta}(\mathrm{s})\end{array}$ & $\begin{array}{c}\text { Stretching } \\
\text { parameter }(\beta)\end{array}$ & $\begin{array}{c}\text { Transport } \\
\text { number }\left(\mathrm{t}_{\text {ion }}\right)\end{array}$ \\
\hline S1 & $5.94 \times 10^{-6}$ & 0.47 & $1.27 \mathrm{E}+07$ & $1.18 \mathrm{E}-10$ & $1.24994 \mathrm{E}-4$ & 0.69 & 0.97 \\
S2 & $1.65 \times 10^{-5}$ & 0.39 & $3.19 \mathrm{E}+07$ & $1.57 \mathrm{E}-10$ & $9.92865 \mathrm{E}-6$ & 0.71 & 0.96 \\
S3 & $5.73 \times 10^{-5}$ & 0.32 & $4.01 \mathrm{E}+07$ & $4.33 \mathrm{E}-10$ & $4.97611 \mathrm{E}-6$ & 0.61 & 0.99 \\
S4 & $2.83 \times 10^{-4}$ & 0.31 & $6.35 \mathrm{E}+07$ & $1.35 \mathrm{E}-09$ & $1.98103 \mathrm{E}-6$ & 0.67 & 0.99 \\
S5 & $1.70 \times 10^{-4}$ & 0.53 & $1.26 \mathrm{E}+07$ & $4.10 \mathrm{E}-09$ & $9.4626 \mathrm{E}-6$ & - & 0.97 \\
\hline
\end{tabular}




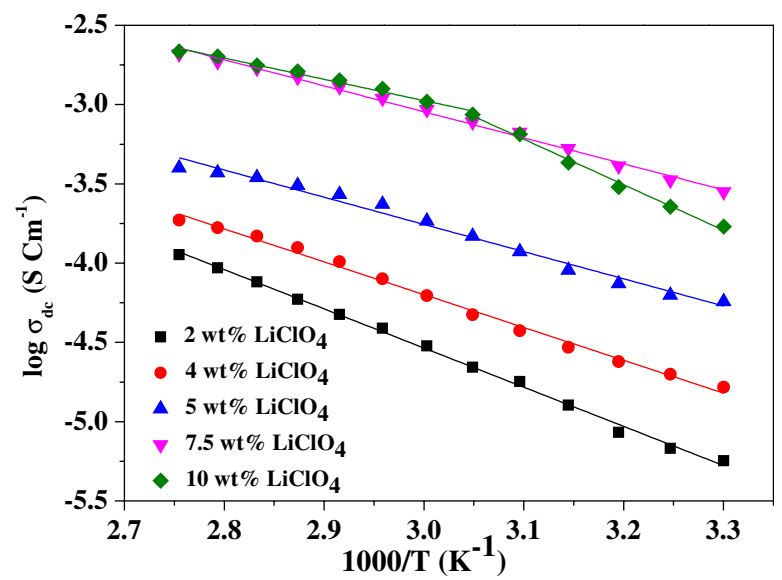

Fig. 6. Temperature dependence of ionic conductivity of GPE with different concentrations of $\mathrm{LiClO}_{4}$.

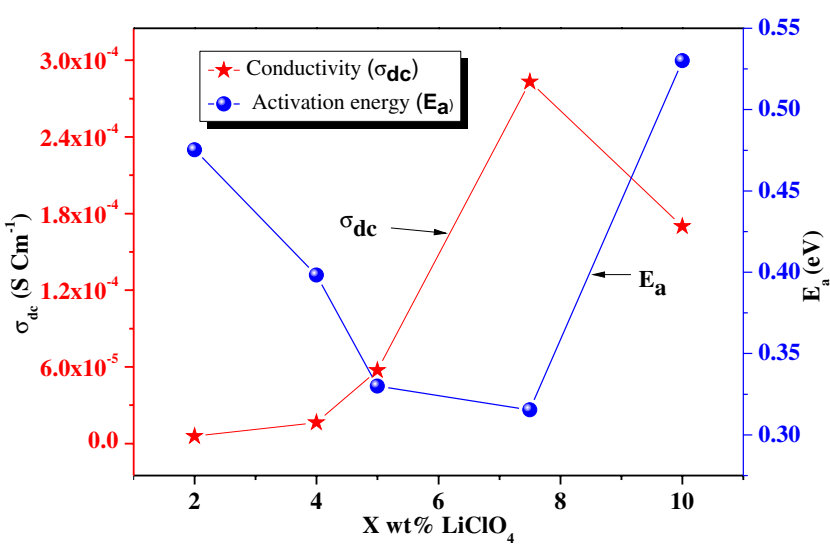

Fig. 7. Conductivity and activation energy versus concentration of $\mathrm{LiClO}_{4}$

high conducting sample, low activation energy $\left(E_{\mathrm{a}}\right)$ is required to acivate the lithium ion for the physical transportation through polymer matrix which is caused by the completely amorphous nature. ${ }^{32}$ According to Li et al. ${ }^{33}$ ions or cluster of ions migrate in the pores of polymer, amorphous domains swelled by electrolyte and along molecular chain of polymer. The migration of lithium ion along the molecular chains of polymer is not appreciable. Hence, it can be stated that increase in conductivity may be due to filled pores with electrolyte and swelled amorphous domain. Thereafter, ion clusters are formed, which mitigate the process of conduction in the polymer electrolyte.

\subsection{Frequency dependent ionic conductivity}

Figure 8 shows the variation of conductivity as a function of frequency at different temperatures for $4 \mathrm{wt} . \% \mathrm{LiClO}_{4}$ salt in the GPE system. It is observed from the figure that the frequency-dependent conductivity involves general features which consist of three different regions, (i) a low frequency

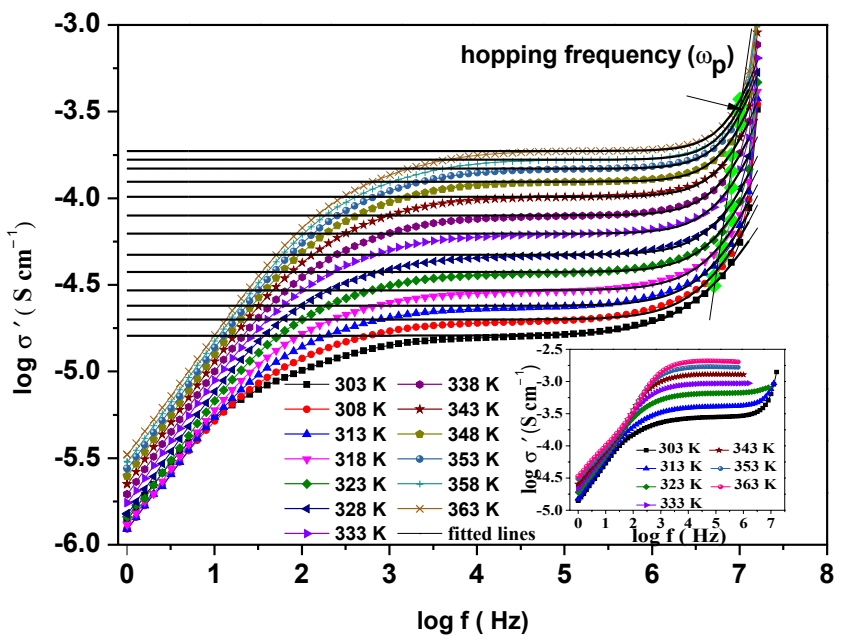

Fig. 8. Variation of conductivity as a function of frequency of GPE with 4 wt. $\% \mathrm{LiClO}_{4}$ at different temperatures and the inset shows the variation of conductivity as a function of frequency of GPE with 7.5 wt. $\% \mathrm{LiClO}_{4}$ at different temperatures.

dispersive region, (ii) an intermediate frequency plateau region, and (iii) a high frequency dispersion region. ${ }^{34,35}$ At lower frequency region, electrode polarization starts with a simultaneous sharp decrease in $\sigma^{\prime}(\omega)$. This feature may be due to the accumulation of more charges at the electrodeelectrolyte interface at low frequency. A low frequency region is followed by an intermediate frequency plateau region in which $\sigma^{\prime}(\omega)$ remains frequency independent upto a certain frequency. This can be ascribed to the macroscopic DC conductivity of the materials. At intermediate frequency, ions travel much faster and jump from one site to another available site. Successful hop of ion to a neighboring vacant site contributes to the DC conductivity when the frequency is lower than the hopping frequency $\left(\omega_{p}\right)$. When the frequency exceeds to hopping frequency $\left(\omega_{p}\right)$, the conductivity continues to increase with the increase in frequency. The crossover from the frequency-independent conductivity to the conductivity dispersion indicates that the conductivity relaxation phenomena is occurring. This behavior of the ionic conductivity is according to Jonschers power law: $\sigma(\omega)=\sigma_{\mathrm{DC}}+A \omega^{n}$, where $\sigma_{\mathrm{DC}}$ is the frequency independent DC conductivity, $A$ is the pre-exponential constant, $\omega$ is the angular frequency, and $n$ is the power law exponent. Using the above equation, the fitting parameters $\sigma_{\mathrm{DC}}, A$, and $n$ are obtained. AC conductivity studies also provide information about conductivity relaxation. The ionic conductivity is also ascribed by the factors like concentration of mobile charge carriers and hopping frequency of charge carriers ${ }^{35}$ which are estimated by the following equations:

$$
\begin{gathered}
\omega_{p}=\left(\frac{\sigma_{\mathrm{DC}}}{A}\right)^{\frac{1}{n}}, \\
K=\frac{\sigma_{\mathrm{DC}} T}{\omega_{p}} .
\end{gathered}
$$


From Fig. 8, it is clear that the hopping frequency (shown with solid line) increases with the rise in temperature. This is because increase in temperature results in the expansion of polymer which facilitates the local empty spaces and expands the free volume. These promote the segments and $\mathrm{Li}$ ion to move. Consequently, hopping movement of ions is favored and the ions can hop with higher frequency and shorter relaxation time. The AC conductivity plot of higher conducting sample (inset of Fig. 8) does not show high frequency dispersion region as the temperature is increased since the hopping frequency of charge carrier increases or relaxation time is too short to be observed in our system. The shifting of frequency dispersion region of $\mathrm{AC}$ conductivity spectrum towards the higher frequency side with rise in temperature is reported by Gondaliya et $\mathrm{al.}^{36}$ in plasticized PEO$\mathrm{AgCF}_{3} \mathrm{SO}_{3}-\mathrm{SiO}_{2}$ polymer electrolyte system.

The calculated values of hopping frequency $\left(\omega_{p}\right)$ and mobile carrier concentration factor $(K)$ for GPE samples containing different salt concentrations at $303 \mathrm{~K}$ are tabulated in Table 4. It is observed that as concentration of $\mathrm{LiClO}_{4}$ increases, the transition from frequency-independent plateau region to the $\mathrm{AC}$ conductivity dispersion region shift towards the higher frequency side. ${ }^{37}$ The increase in the hopping frequency leads to a conclusion that the higher the conductivity of the sample, the shorter is its relaxation time. ${ }^{38}$ The carrier concentration term $K$ is following the same trend as conductivity data with increasing salt concentration except GPE containing $10 \mathrm{wt} . \% \mathrm{LiClO}_{4}$ where hopping frequency decreases.

To attain better insight on the ion dynamics within polymer electrolyte, the study of scaling behavior of the conductivity spectra is analyzed. The scaling (time temperature superposition principle/thermorheological simplicity) is a tool to examine whether conduction mechanism involving ion dynamics is temperature-dependent or not. Various scaling laws have been proposed for scaling the AC conductivity data. ${ }^{39-43}$

In the present study, Ghosh ${ }^{42}$ scaling technique is followed in which the AC conductivity is scaled by the DC conductivity $\sigma_{\mathrm{DC}}$ and the frequency by the crossover frequency $f_{p}$ which is obtained by fitting conductivity data with power law $\sigma(\omega)=\sigma_{\mathrm{DC}}+A \omega^{n}$.

$$
\frac{\sigma^{\prime}}{\sigma_{\mathrm{DC}}}=F\left(\frac{f}{f_{p}}\right)
$$

Scaling of the GPE sample containing 4 wt. $\% \mathrm{LiClO}_{4}$ at different temperatures is shown in Fig. 9, from which we note that the scaled spectra at different temperatures for a composition almost merge on a common master curve except a deviation at lower frequencies which might be due to the electrode polarization effect. Thus, we conclude that the relaxation dynamics of charge carriers in the electrolyte follow a common mechanism throughout the entire temperature range which indicates the temperature-independent nature of ion conduction mechanism. ${ }^{44}$

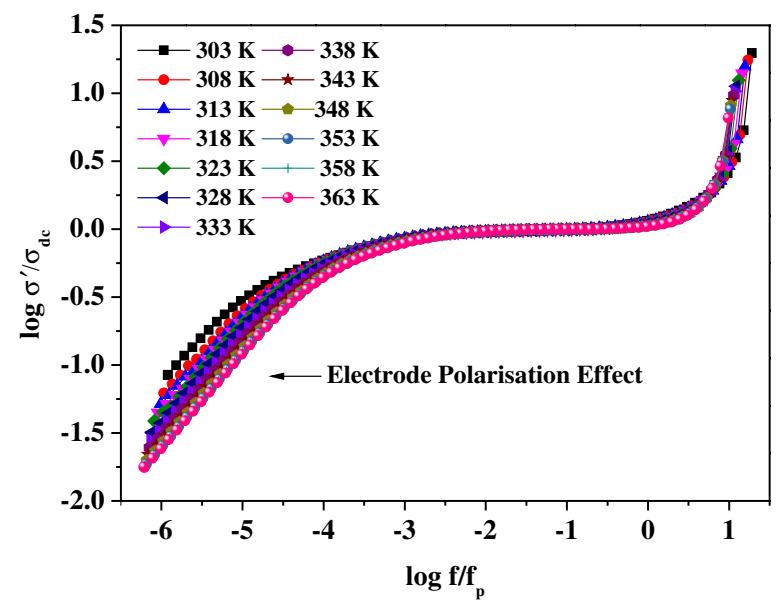

Fig. 9. Scaled conductivity spectra of GPE containing $4 \mathrm{wt} . \%$ $\mathrm{LiClO}_{4}$, respectively.

\subsection{Dielectric study}

Dielectric study helps understand the polarization effect at the electrode-electrolyte interface and the conductivity behavior. The frequency-dependent complex dielectric permittivity is given by $\varepsilon^{*}=\varepsilon^{\prime}+j \varepsilon^{\prime \prime}$, where $\varepsilon^{\prime}$ and $\varepsilon^{\prime \prime}$ are the real and imaginary parts of the dielectric permittivity, known as dielectric constant and dielectric loss, respectively. The significance of these polymer dielectric constant and dielectric loss is to explore the ion conduction and relaxation mechanism. The dielectric constant is a measure of the materials polarization which is associated with the storage of electric charge and also represents the amount of dipole alignment in a given volume. ${ }^{45}$ The equation for the dielectric constant $\left(\varepsilon^{\prime}\right)$ is

$$
\varepsilon^{\prime}=\frac{Z^{\prime \prime}}{\omega C_{0}\left(Z^{\prime 2}+Z^{\prime \prime 2}\right)},
$$

where $Z^{\prime}$ and $Z^{\prime \prime}$ are the real and imaginary parts of the impedance, $\omega$ is angular frequency, and $C_{0}$ is the vacuum capacitance.

The dielectric constant $\left(\varepsilon^{\prime}\right)$ and dielectric loss $\left(\varepsilon^{\prime \prime}\right)$ as a function of frequency for GPE with $5 \mathrm{wt} \%$ of $\mathrm{LiClO}_{4}$ at different temperatures are shown in Fig. 10.

At lower frequency region, there is a sharp increase in dielectric constant $\left(\varepsilon^{\prime}\right)$ which indicates the existence of space charge polarization due to the building up of charge at the interface because of slow periodic reversal effect of the applied field. ${ }^{46}$ Hence, the large value of $\varepsilon^{\prime}$ is obtained at lower frequencies. While at high frequency, because of fast periodic reversal effect of the electric field, diffusion of ions is not feasible and incapability of dipoles to orient themselves in the direction of the applied alternating field. Hence, the decrease in the value of $\varepsilon^{\prime}$ has been observed with increasing frequency. It is also revealed from Fig. 10 that the dielectric constant increases with increasing temperatures form $303 \mathrm{~K}$ 


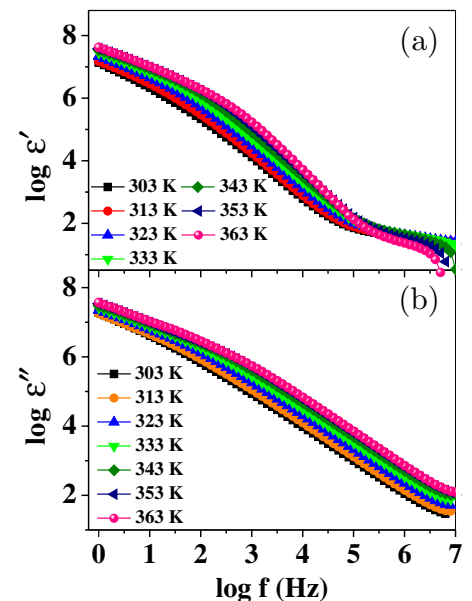

Fig. 10. (a) $\varepsilon^{\prime}$ (dielectric constant) versus $\log f$ (b) $\varepsilon^{\prime \prime}$ (dielectric loss) versus $\log f$ for GPE containing $5 \mathrm{wt} . \% \mathrm{LiClO}_{4}$ at different temperatures.

to $363 \mathrm{~K}$ which is due to the decrease in viscosity of GPE and increasing amorphous nature that facilitates the dipole orientation due to greater freedom of movement of dipole molecular chain of the polymer electrolyte. The dielectric loss $\left(\varepsilon^{\prime \prime}\right)$ becomes very large at lower frequencies due to free charge motion within the materials and it decreases with the increase in frequency. However, relaxation effect is masked due to the presence of high conductivity of the material.

Salt concentration dependence of the dielectric constant at $100 \mathrm{~Hz}, 1 \mathrm{KHz}$, and $10 \mathrm{KHz}$ is plotted in Fig. 11. It is clear from the figure that the trend observed for dielectric constant is the same as the trend followed by DC conductivity versus salt concentration of $\mathrm{LiClO}_{4}$ salt as studied in the previous section. The highest conducting sample has the highest value of $\varepsilon^{\prime}$.

At room temperature, the incorporation of $\mathrm{LiClO}_{4}$ up to $7.5 \mathrm{wt} . \%$ within the matrix increased the dielectric permittivity $\varepsilon^{\prime} \approx 4.37 \mathrm{E}+03$ to $1.35 \mathrm{E}+06$ at $100 \mathrm{~Hz}$ due to the increased number density of charge carriers as a result of the

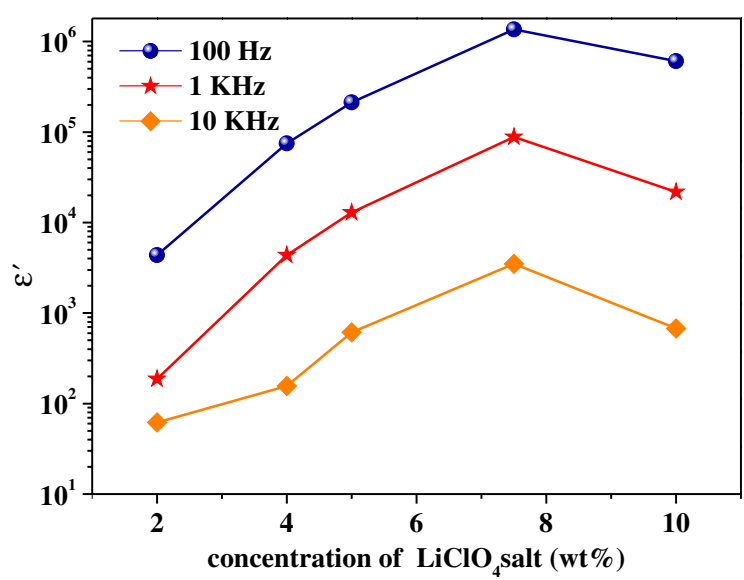

Fig. 11. Variation of dielectric constant with salt concentration variations at $100 \mathrm{~Hz}, 1 \mathrm{KHz}$, and $10 \mathrm{KHz}$. salt dissociation in the polymer matrix. ${ }^{47}$ At $10 \mathrm{wt} . \%$ of salt content, Coulomb interaction between $\mathrm{Li}^{+}$cations and $\mathrm{ClO}_{4}^{-}$ anions increases, leading to the re-association of ions to form ion pairs or ion clusters which reduce the mobile charge carrier density and hence their contribution toward electrode polarization thus reduces the value of $\varepsilon^{\prime} .{ }^{47}$

\subsubsection{Correlation between $Z^{\prime \prime}$, tan delta (tan $\delta$ ) and AC conductivity $\left(\boldsymbol{\sigma}^{\prime}\right)$}

Figure 12 shows the $Z^{\prime \prime}$ and $\tan \delta$ versus $\log f$ for the GPE sample with 5 wt. $\% \mathrm{LiClO}_{4}$ at $308 \mathrm{~K}$. Both $Z^{\prime \prime}$ and $\tan \delta$ show the characteristic peak at different frequencies indicating the occurrence of different relaxation phenomena. The frequency corresponding to $Z_{\max }^{\prime \prime}$ peak of conductivity relaxation can be correlated with the frequency corresponding to a change in ion transport from $\mathrm{AC}$ (high frequency dispersion region) to DC (plateau region) in AC conductivity plot (Fig. 12(b)), whereas the peak of $\tan \delta$ corresponds to the dielectric relaxation where the electrode polarization starts. Furthermore, more information on the relaxation phenomena of system with the variation of salt concentrations is obtained from the plot of loss tangent $(\tan \delta)$ as a function of frequency.

The value of $\tan \delta$ is calculated using the following equation:

$$
\tan \delta=\frac{\varepsilon^{\prime \prime}}{\varepsilon^{\prime}}=\frac{Z^{\prime}}{Z^{\prime \prime}}
$$

Figure 13 shows $\tan \delta$ versus $\log f$ curves for GPE for different concentrations of salt at $303 \mathrm{~K}$. This loss tangent plot consists of well-defined peak at characteristic frequency.

The relation between relaxation time $\left(\tau_{\tan \delta}\right)$ and frequency corresponding to peak $\left(f_{p}\right)$ is

$$
\tau_{\tan \delta}=\frac{1}{2 \pi f_{p}} .
$$

The loss peak is observed to shift toward higher frequency with increasing salt concentration until $7.5 \mathrm{wt} . \% \mathrm{LiClO}_{4}$, thus

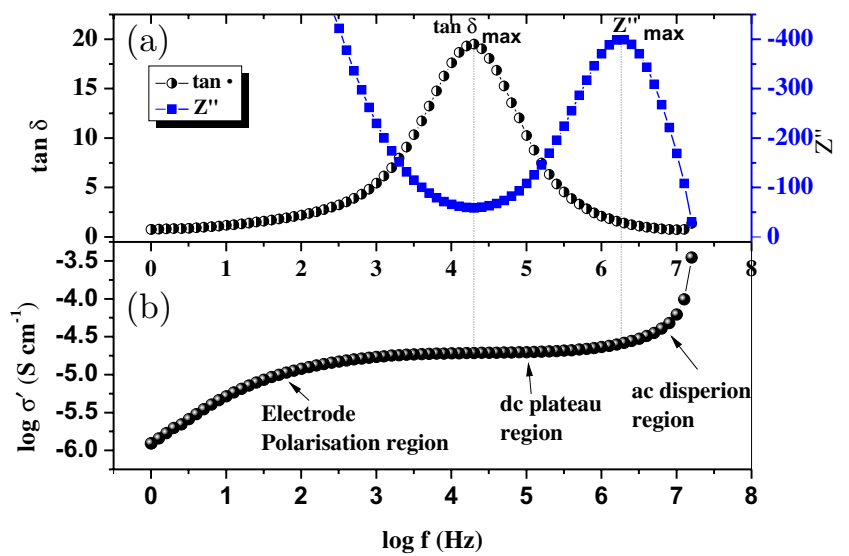

Fig. 12. (a) $Z^{\prime \prime}$ and $\tan \delta$ versus $\log f$ (b) $\log \sigma^{\prime}$ versus $\log f$ for the GPE containing 4 wt. $\%$ of $\mathrm{LiClO}_{4}$ at $308 \mathrm{~K}$. 


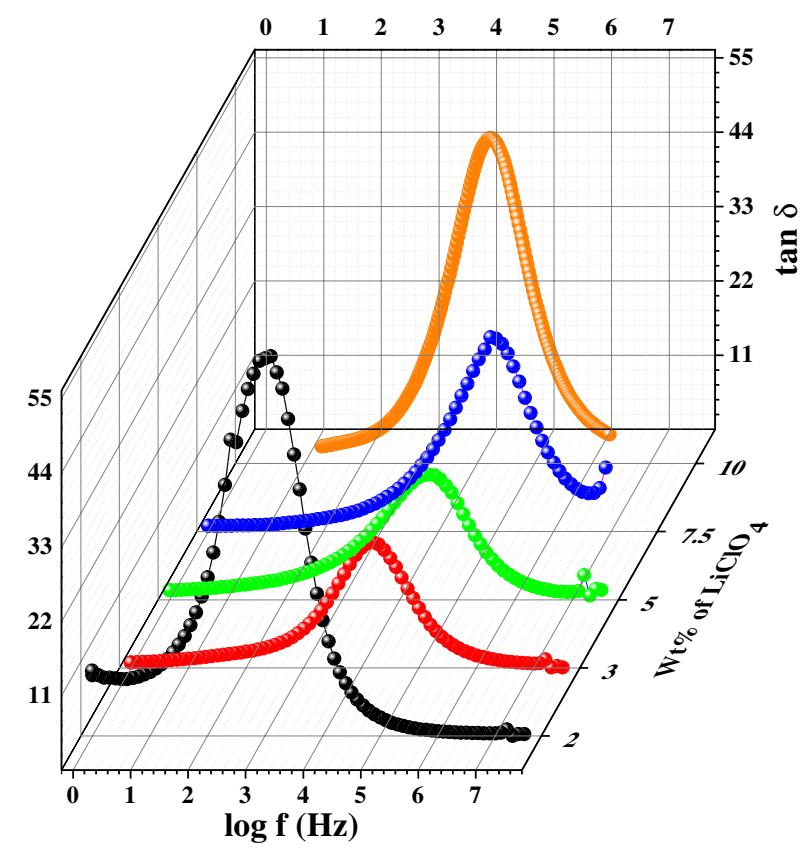

Fig. 13. Variation of loss tangent versus $\log f$ for GPE with different concentrations of $\mathrm{LiClO}_{4}$ at $303 \mathrm{~K}$.

reducing relaxation time. The obtained value of relaxation times are listed in Table 4. The change in the relaxation time is inverse of the DC conductivity variation. The reduction in relaxation time indicates that polymer chain can easily orient through increased amorphous region and/or empty room by incorporating more amounts of salt.

\subsection{Modulus study}

Modulus formalism has been used for further analysis of impedance data which suppresses the electrode-electrolyte polarization effect at lower frequency and highlights the bulk effect at higher frequency. This can be used to study conductivity relaxation behavior. The electric modulus $M^{*}$ is defined as $M^{*}=M^{\prime}+j M^{\prime \prime}$ or $M^{*}=j \omega C_{0} Z^{*}$, where $M^{\prime}$ and $M^{\prime \prime}$ are the real and imaginary parts of modulus, respectively. ${ }^{48}$

Figure 14 shows the $M^{\prime \prime}$ as a function of $\log f$ for different salt concentrations at $303 \mathrm{~K}$. It shows the characteristic peak at particular frequency $\left(f_{\max }\right)$ where the value of $M^{\prime \prime}$ is maximum. According to Sharma et al. ${ }^{48}$ the frequency region where $f<f_{\max }$ corresponds to long-range mobility and higher frequency $\left(f>f_{\max }\right)$ part is attributed to ions spatially confined in narrow potential well and the frequency range where peak occurs indicates the transition between long- and short-range mobility.

It is also observed that the position of the peak maximum is shifted to higher frequencies and the height of the peak at high frequency changes with salt concentration. This behavior suggests that the charge carrier hopping has taken place due to the addition of lithium salt due to the increase in

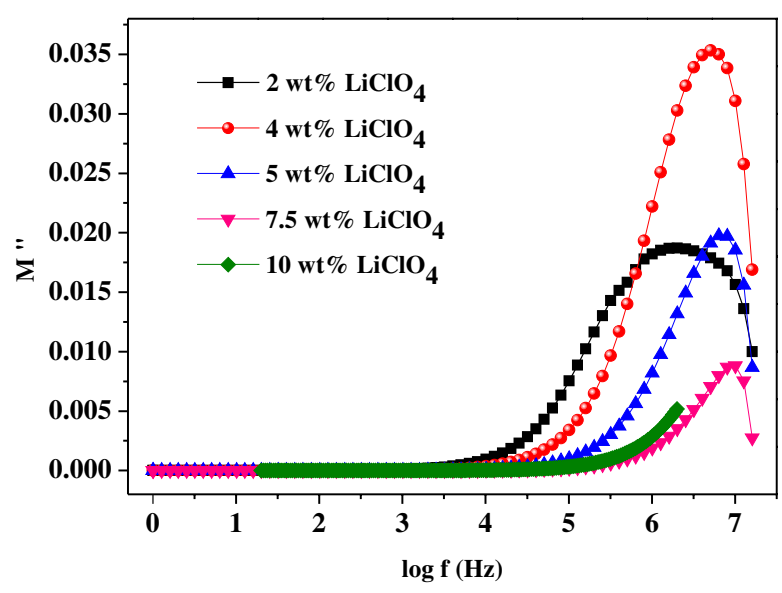

Fig. 14. Variations in imaginary part of modulus $\left(M^{\prime \prime}\right)$ versus $\log f$ for GPE with different concentrations of $\mathrm{LiClO}_{4}$ at $303 \mathrm{~K}$.

the amorphous nature of GPE which indicates the occurrence of a relaxation phenomenon. Similar feature has also been reported by Karmakar et al. ${ }^{49}$ in $\mathrm{PEO}-\mathrm{LiClO}_{4}$ electrolyte system.

In addition to these, the asymmetric and broad nature (broader than ideal Debye peak) of the peaks in $M^{\prime \prime}$ curve can be interpreted as being the consequence of the distribution of relaxation time and nonexponential behavior of the conductivity relaxation. ${ }^{50}$ The complex electric modulus in the form of a Fourier transform is given by the following relation:

$$
M_{\infty}\left[1-\int_{0}^{\infty} \exp (-i \omega t) \frac{d \phi(t)}{d t}\right] .
$$

$M_{\infty}=\frac{1}{\varepsilon_{\infty}}$, where $\varepsilon_{\infty}$ is the limiting high frequency real part of permittivity and the function $\phi(t)$ is the relaxation function or Kohlrauch-Williams-Watts (KWW) function represented by ${ }^{49}$

$$
\phi(t)=\exp \left(\frac{-t}{\tau}\right)^{\beta}
$$

where $\beta$ is the nonexponential parameter, $0<\beta<1$ is an exponent indicating departure from the debye relaxation $(\beta=1)$, and $\tau$ is the relaxation time. The parameter $\beta$ for the samples are calculated using the formula $\beta=1.14 / \mathrm{FWHM}$ and are listed in Table 4. From Table 4, it is noted that the values of $\beta$ are less than one, which suggests a greater departure from the ideal Debye response.

The spectroscopic plot, i.e., graphs of $Z^{\prime \prime}$ and $M^{\prime \prime}$ versus $\log f$ offers a convenient way of presenting the data as suggested by Grant et al. ${ }^{51}$ They reported the normalized modulus and impedance spectra for ideal solid electrolyte (single RC element) were completely superposable, which can be interpreted as ideal Debye Curve. The plot of $Z^{\prime \prime}$ and $M^{\prime \prime}$ versus $\log f$ for the sample containing 4 wt.\% of $\mathrm{LiClO}_{4}$ at $308 \mathrm{~K}$ is shown in Fig. 15. The maxima of $Z^{\prime \prime}$ and $M^{\prime \prime}$ do not coincide at the same frequency. The peak of $Z^{\prime \prime}$ is at lower frequency side, whereas peak of $M^{\prime \prime}$ is at higher frequency 


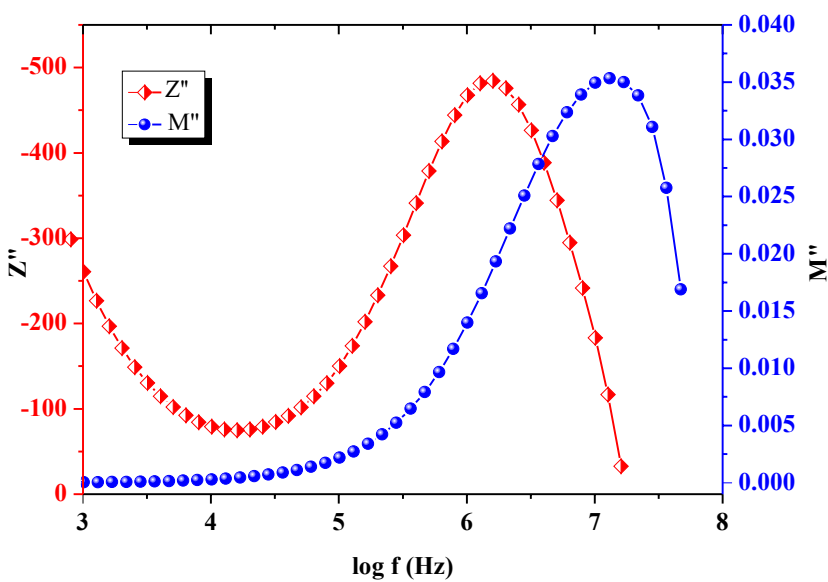

Fig. 15. Spectroscopic plot $\left(\mathrm{Z}^{\prime \prime}\right.$ and $\mathrm{M}^{\prime \prime}$ versus $\log f$ ) for the GPE containing 4 wt. $\%$ of $\mathrm{LiClO}_{4}$ at $308 \mathrm{~K}$.

side having broadened nature indicating wide distribution of relaxation times, i.e., (PVDF-HFP:PMMA)-(PC:DEC)$\mathrm{LiClO}_{4}$-based GPE films confirm non-Debye nature.

\subsection{Transport number measurements}

For polymer electrolytes to be used in rechargeable battery applications, the main charge carriers should be ions or ionic conductivity should be mainly due to ions only. That is, the fractional contribution of ionic conductivity to the total conductivity should be as close to unity as possible and the fractional contribution of the electronic conductivity should be negligibly small (close to zero). Therefore, it is necessary to determine the fraction of the conductivity due to ions and electrons. The ionic transport numbers $\left(t_{\text {ion }}\right)$ for the (PVDFHFP:PMMA)-(PC:DEC)- $\mathrm{LiClO}_{4}$ GPEs were determined by means of the DC polarization technique. ${ }^{52}$ In this technique, the polarization current was monitored as a function of time upon the application of a fixed DC voltage across the

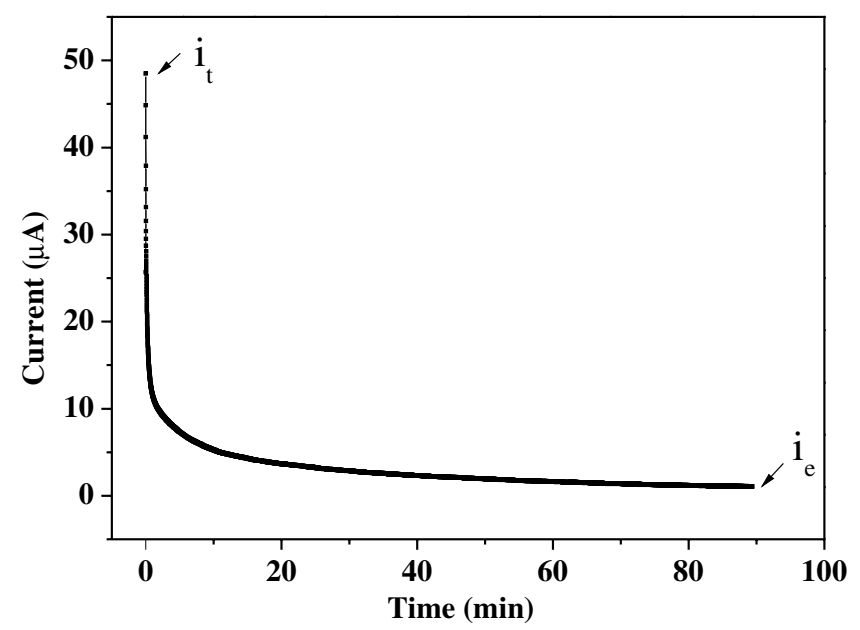

Fig. 16. Polarization current as a function of time for GPE with 4 wt. $\% \mathrm{LiClO}_{4}$. (stainless steel SS)/GPE/SS cell. The measured current versus time data is plotted for GPE and is shown in Fig. 16.

The ionic transport numbers are calculated from the polarization current versus time plot by using Eq. (2). The calculated transport numbers are listed in Table 4. For all the blended polymer gel electrolyte system, the values of the ionic transport number are measured in the range of $0.96-0.99$. This suggests that the charge transport in these polymer electrolytes is mainly due to ions and only a negligible contribution comes from electrons. ${ }^{53}$

\section{Conclusions}

- In the present study, gel polymer blend membranes composed of (PVDF-HFP:PMMA)-(PC:DEC): $\mathrm{LiClO}_{4}$ with different amounts of $\mathrm{LiClO}_{4}$ salt were prepared by a solution casting technique.

- A substantial enhancement in conductivity was observed with the addition of $\mathrm{LiClO}_{4}$. We obtained the maximum ionic conductivity of $2.83 \times 10^{-4} \mathrm{~S} \mathrm{~cm}^{-1}$ for the sample with $7.5 \mathrm{wt} . \% \mathrm{LiClO}_{4}$. The increase in the ionic conductivity up to salt concentration of $7.5 \mathrm{wt} . \% \mathrm{LiClO}_{4}$ is due to increase in the amorphicity in the gel polymer blend. XRD result, FTIR spectra, and SEM micrographs strongly support our results. At 10 wt. $\%$ of $\mathrm{LiClO}_{4}$, the ionic conductivity decreases due to the increase in crystalline nature of GPE.

- The ionic conductivity is temperature-dependent and follows the Arrhenius relation for all systems confirming that ion transport mechanism through hopping mechanism decoupled from polymer chain segmental motion. The lowest activation energy of $0.31 \mathrm{eV}$ and highest conductivity for the sample containing $7.5 \mathrm{wt} . \%$ of $\mathrm{LiClO}_{4}$ are due to ease of hopping of ions through amorphous and swelled regions (regions filled with electrolyte) of GPE. This sample possesses lowest relaxation time and shows the presence of micropores which provides pathway for diffusion of ions.

- The increase in the dielectric constant with increasing temperatures as well as salt content reveal the availability of ions due to the dissociation of ion pair and increased amorphicity. The different peak positions of $\mathrm{Z}^{\prime \prime}$ and $\mathrm{M}^{\prime \prime}$ spectra confirm the distributed relaxation time and nonDebye nature of the gel electrolyte system. The lower value of $\beta(<1)$ indicates greater departure from ideal Debyetype behavior.

- The high conductivity and ionic transport number (near unity) suggest that these electrolytes are suitable for use in electrochemical devices, especially in lithium ion battery.

\section{References}

${ }^{1}$ A. M. Stephan, Review on gel polymer electrolytes for lithium batteries, Eur. Polym. J. 42, 21 (2006). 
${ }^{2}$ B. Scrosati, Recent advances in lithium ion battery materials, Electrochimica Acta 45, 2461 (2000).

${ }^{3}$ J. Fang, J. Qiao, D. P. Wilkinson and J. Zhang (eds.), Electrochemical Polymer Electrolyte Membranes (CRC Press, 2015).

${ }^{4}$ L. Long, S. Wang, M. Xiao and Y. Meng, Polymer electrolyte for lithium polymers batteries, J. Mater. Chemis. A 4, 10038 (2016).

${ }^{5}$ L. N. Sim and S. M. nad, A. K. Arof, Ftir studies of PEMA/ PVDF- HFP blend polymer electrolyte system incorporated with $\mathrm{LiCF}_{3} \mathrm{SO}_{3}$ salt, Vibr. Spectroscopy 58, 57 (2012).

${ }^{6}$ F. Groce, F. Gerace, G. Dautzemberg, S. Passerini, G. Appetecchi and B. Scrosati, Synthesis and characterization of highly conducting gel electrolytes, Electrochimica Acta 39, 2187 (1994).

${ }^{7}$ G. Appetecchi, F. Croce and B. Scrosati, Kinetics and stability of the lithium electrode in poly(methylmethacrylate)-based gel electrolytes, Electrochimica Acta 40, 991 (1995).

${ }^{8}$ N. Krishna Jyothi, K. Vijaya Kumar, G. Sunita Sundari and P. Narayana Murthy, Ionic conductivity and battery characteristic studies of a new PAN-based $\mathrm{Na}+$ ion conducting gel polymer electrolyte system, Ind. J. Phys. 90, 289 (Mar 2016).

${ }^{9}$ A. Subramania, N. T. K. Sundaram, A. R. Priya, R. Gangadharan and T. Vasudevan, Preparation of a microporous gel polymer electrolyte with a novel preferential polymer dissolution process for Li-ion batteries, J. Appl. Polym. Sci. 98, 1891 (2005).

${ }^{10}$ M. Zhang, M. Li, Z. Chang, Y. Wang, J. Gao, Y. Zhu, Y. Wu and W. Huang, A sandwich PVDF/HEC/PVDF gel polymer electrolyte for lithium ion battery, Electrochimica Acta 245, 752 (2017).

${ }^{11}$ H. Choe, J. Giaccai, M. Alamgir and K. Abraham, Preparation and characterization of poly(vinyl sulfone)- and poly(vinylidene fluoride)-based electrolytes, Electrochimica Acta 40, 2289 (1995), International symposium on polymer electrolytes.

${ }^{12}$ R. Miao, B. Liu, Z. Zhu, Y. Liu, J. Li, X. Wang and Q. L. and, PVDF-HFP- based porous polymer electrolyte membranes for lithium-ion batteries, J. Power Sources 184, 420 (2008).

${ }^{13}$ A. Stephan and K. Nahm, Review on composite polymer electrolytes for lithium batteries, Polymer 47, 5952 (2006).

${ }^{14}$ A. M. Stephan, S. Kumar, N. Renganathan and M. Kulandainathan, Characterization of poly (vinylidene fluoridehexafluoropropylene)(PVDFHFP) electrolytes complexed with different lithium salts., Eur. Polym. J. 41, 15 (2005).

${ }^{15}$ L.N. Sim, S. Majid and A. Arof, Characteristics of PEMA/PVDFHFP blend polymeric gel films incorporated with lithium triflate salt in electrochromic device, Solid State Ionics 209, 15 (2012).

${ }^{16} \mathrm{P}$. Prabakaran and R. Manimuthu, Enhancement of the electrochemical properties with the effect of alkali metal systems on PEO/PVDF-HFP complex polymer electrolytes, Ionics 22, 827 (2016).

${ }^{17}$ K. Isa, Z. Osman, A. Arof, L. Othman, N. Zainol, S. M. Samin, W. Chong and N. Kamarulzaman, Lithium ion conduction and ionpolymer interaction in PVDF-HFP based gel polymer electrolytes, Solid State Ionics 268, 288 (2014).

${ }^{18}$ X. Flora, M. Ulaganathan and S. Rajendran, Role of different plasticizers in li-ion conducting Poly(Acrylonitrile)-Poly(Methyl Methacrylate) hybrid polymer electrolyte, Int. J. Polymer. Mater. Polymer. Biomater. 62, 737 (2013).

${ }^{19}$ S. A. Hashmi, A. Kumar and S. K. Tripathi, Experimental studies on poly methyl methacrylate based gel polymer electrolytes for application in electrical double layer capacitors, J. Phys. D: Appl. Phys. 40, 6527 (2007).
${ }^{20}$ A. Stephan, K. Nahm, M. Kulandainathan, G. Ravi and J. Wilson, Poly(vinylidene fluoride-hexafluoropropylene)(PVDF-HFP) based composite electrolytes for lithium batteries, Eur. Polym. J. 42, 1728 (2006).

${ }^{21}$ M. Ulaganathan, R. Nithya, S. Rajendran and S. Raghu, Li-ion conduction on nanofiller incorporated PVDF-co-HFP based composite polymer blend electrolytes for flexible battery applications, Solid State Ionics 218, 7 (2012).

${ }^{22}$ P. Prabakaran and R. P. Manimuthu, Enhancement of the electrochemical properties with the effect of alkali metal systems on PEO/PVDF-HFP complex polymer electrolytes, Ionics 22, 827 (Jun 2016).

${ }^{23}$ N. Shukla and A. K. Thakur, Role of salt concentration on conductivity optimization and structural phase separation in a

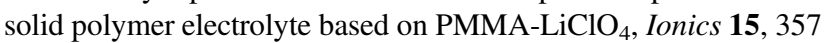
(2009).

${ }^{24}$ P. Sharma, D. K. Kanchan and N. Gondaliya, Effect of ethylene carbonate concentration on structural and electrical properties of PEO-PMMA polymer blends, Ionics 19, 777 (2013).

${ }^{25}$ Z. Li, G. Su, D. Gao, X. Wang and X. Li, Effect of $\mathrm{Al}_{2} \mathrm{O}_{3}$ nanoparticles on the electrochemical characteristics of P(VDF-HFP)based polymer electrolyte, Electrochimica Acta 49, 4633 (2004).

${ }^{26} \mathrm{~S}$. Ramesh and S. Lu, A simple P(VdF-HFP) LiTf system yielding highly ionic conducting and thermally stable solid polymer electrolytes, J. Molecular Liquids 177, 73 (2013).

${ }^{27}$ A. K. Arof, S. Amirudin, S. Z. Yusof and I. M. Noor, A method based on impedance spectroscopy to determine transport properties of polymer electrolytes, Phys. Chem. Chem. Phys. 16, 1856 (2014).

${ }^{28}$ S. Rajedran, V. Bamaand and M. Prabhu, Effect of lithium salt concentration in PVAc/PMMA-based gel polymer electrolytes, Ionics 16, 27 (2010).

${ }^{29}$ S. Ramesh and S. Lu, Effect of lithium salt concentration on crystallinity of poly(vinylidene fluoride-co-hexafluoropropylene)based solid polymer electrolytes, J. Molecular Struct. 994, 403 (2011).

${ }^{30}$ M. A. Ratner, P. Johansson and D. F. Shriver, Polymer electrolytes: Ionic transport mechanisms and relaxation coupling, MRS Bullet. 25, 3137 (2000).

${ }^{31}$ C. Mathew, K. Kesavan and S. Rajendran, Analysis of plasticizer influence in Poly(vinyl acetate)/Poly(vinylidene fluoride) polymer blend electrolyte, Ionics 20, 439 (2014).

${ }^{32}$ M. Hema, S. Selvasekaranpandian, H. Nithya, A. Sakunthala and D. Arunkumar, Structural and ionic conductivity studies on proton conducting polymer electrolyte based on polyvinyl alcohol, Ionics 15, 487 (2009).

${ }^{33}$ Z. Li, G. Su and X. W. D. Gao, Micro-porous P(VDF-HFP)-based polymer electrolyte filled with $\mathrm{Al}_{2} \mathrm{O}_{3}$ nanoparticles, Solid State Ionics 176, 1903 (2005).

${ }^{34}$ Z. Osman, M. Ghazali, L. Othman and K. Isa, Ac ionic conductivity and dc polarization method of lithium ion transport in PMMA-LiBF 4 gel polymer electrolytes, Result Phys. 2, 1 (2012).

${ }^{35}$ N. Shukla, A. K. Thakur and A. S. D. T. Marks, Ion conduction mechanism in solid polymer electrolyte: An applicability of almond-west formalism, Int. J. Electrochem. Sci. 9, 7644 (2014). ${ }^{36}$ N. Gondaliya, D. K. Kanchan, P. Sharma and M. S. Jayswal, Dielectric and electric properties of plasticized PEO- $\mathrm{AgCF}_{3} \mathrm{SO}_{3}$ $\mathrm{SiO}_{2}$ nanocomposite polymer electrolyte system, Polym. Composit. 33, 2195 (2012). 
${ }^{37}$ C. S. Ramya, T. Savitha, S. Selvasekarapandian and G. Hirankumar, Transport mechanism of $\mathrm{Cu}$-ion conducting PVA based solid-polymer electrolyte, Ionics 11, 436 (2005).

${ }^{38}$ R. H. Y. Subban and A. K. Arof, Impedance spectroscopic studies on a binary salt poly (vinyl chloride) based electrolyte, Ionics 9 , 375 (2003).

${ }^{39}$ D. L. Sidebottom, Universal approach for scaling the ac conductivity in ionic glasses, Phys. Rev. Lett. 82, 3653 (May 1999).

${ }^{40}$ B. Roling, A. Happe, K. Funke and M. D. Ingram, Carrier concentrations and relaxation spectroscopy: New information from scaling properties of conductivity spectra in ionically conducting glasses, Phys. Rev. Lett. 78, 2160 (Mar 1997).

${ }^{41}$ K. Funke, B. Roling and M. Lange, Dynamics of mobile ions in crystals, glasses and melts, Solid State Ionics 105, 195 (1998).

${ }^{42}$ A. Ghosh and A. Pan, Scaling of the conductivity spectra in ionic glasses: Dependence on the structure, Phys. Rev. Lett. 84, 2188 (Mar 2000).

${ }^{43}$ C. León, P. Lunkenheimer and K. L. Ngai, Test of universal scaling of ac conductivity in ionic conductors, Phys. Rev. B 64, 184304 (Oct 2001)

${ }^{44}$ T. Dam, A. N. Tripathy, M. Paluch, S. S. Jena and D. K. Pradhan, Investigations of relaxation dynamics and observation of nearly constant loss phenomena in $\mathrm{PEO}_{20}-\mathrm{LiCF}_{3} \mathrm{SO}_{3}-\mathrm{ZrO}_{2}$ based polymer nano-composite electrolyte, Electrochimica Acta 202, 147 (2016).

${ }^{45}$ Y. M. Yusof, H. A. Illias and M. F. Z. Kadir, Incorporation of $\mathrm{nh}_{4}$ br in PVA-chitosan blend-based polymer electrolyte and its effect on the conductivity and other electrical properties, Ionics $\mathbf{2 0}$, 1235 (Sep 2014).
${ }^{46}$ M. Kumar, T. Tiwari and N. Srivastava, Electrical transport behaviour of bio-polymer electrolyte system: Potato starch+ ammonium iodide, Carbohydrate Polymers 88, 54 (2012).

${ }^{47}$ H. J. Woo, S. R. Majid and A. K. Arof, Dielectric properties and morphology of polymer electrolyte based on poly( $\varepsilon$-caprolactone) and ammonium thiocyanate, Mater. Chemis. Phys. 134, 755 (2012).

${ }^{48}$ P. Sharma, D. K. Kanchan, N. Gondaliya, M. Pant and M. S. Jayswal, Conductivity relaxation in $\mathrm{Ag}+$ ion conducting PEOPMMA-PEG polymer blends, Ionics 19, 301 (Feb 2013).

${ }^{49}$ A. Karmakar and A. Ghosh, Dielectric permittivity and electric modulus of polyethylene oxide (PEO)- $\mathrm{LiClO}_{4}$ composite electrolytes, Curr. Appl. Phys. 12, 539 (2012).

${ }^{50}$ R. Muchakayala, S. Bhavani, K. Kondamareddy and V. Rao, Investigations on electrical properties of $\mathrm{PVP}: \mathrm{KIO}_{4}$ polymer electrolyte films, 19, 8593 (05 2013).

${ }^{51}$ R. J. Grant, M. D. INGRAM and A. West, An investigation of $\beta$-alumina electrolytes by electric modulus spectroscopy, 22, 729 (07 1977).

${ }^{52}$ D. Kumar and S. A. Hashmi, Ion transport and ionfiller-polymer interaction in poly(methyl methacrylate)-based, sodium ion conducting, gel polymer electrolytes dispersed with silica nanoparticles, J. Power Sources 195, 5101 (2010).

${ }^{53}$ D. Kumar and S. A. Hashmi, Ionic liquid based sodium ion conducting gel polymer electrolytes, Solid State Ionics 181, 416 (2010). 